https://doi.org/10.22364/htqe.2018.14

Jānis Skābardis, Andrejs Gluščuks, Ilvis Ābeḷkalns

FS "Metta”, University of Latvia, Latvia

\title{
ANALYSIS AND USE OF PHYSICAL CHARACTERISTIC TESTS IN THE TRAINING PROCESS FOR FOOTBALL PLAYERS OF DIFFERENT AGES
}

\begin{abstract}
The Objective of the study Analysis and Use of Physical Characteristic Tests in the Training Process for Football Players of Different Ages is to develop the physical characteristic profile of Football School (FS) "Metta" football players based on the data analysis of the applied study, and to assess the practical application towards the improvement of the training process. The authors conducted a study involving $n=61$ football players (boys) in U14 age group, as well as $n=55$ football players in U15 age group and $n=52$ football players in U16 age group. All participants were tested by using a flying $20 \mathrm{~m}$ sprint test, and a modified T agility test and YYIR test (U14 and U15 - $1^{\text {st }}$ level and U16 - $2^{\text {nd }}$ level). U15 FS “Metta" football players are $1.7 \mathrm{~km} / \mathrm{h}$ faster than U14 players and these differences are statistically reliable $(p<0.05)$ with an average effect size $(d=0.94)$. When comparing results obtained from both groups in YYIR1 and T agility tests, the differences are statistically reliable but with a low effect size: $290 \mathrm{~m}(d=0.51)$ and $0.16(d=0.41)$ respectively, in favour of U15. Differences between $\mathrm{U} 15$ and $\mathrm{U} 16$ in the T agility test (turns to rights and left) are statistically reliable $(p<0.05)$ but with low effect size: $0.22(d=0.59)$ and $0.25(d=0.58)$ seconds respectively. U15 football players of FS "Metta," who have been included in the first team, exceed the average indicators in the physical characteristic profiles. In terms of speed, the player is close to the average adult level $(\sim 30 \mathrm{~km} / \mathrm{h})$.
\end{abstract}

Keywords: physical characteristics, football players' profile, physical characteristic test.

\section{Introduction}

The scientific study of football and its training practice dates back to the 1970s (Drust, Green, 2013) when movements of football players in 
various positions were analysed (Reilly, 1976). To improve the performance of football players during competitions, it is necessary to describe the game itself as it stands nowadays according to various parameters: physiological, technical, tactical, physical, etc. Therefore, it is crucial not only to assess the performance of the competition, but also to assess and analyse the training process. It was discovered that the aerobic energy system dominates a player for most of the match. However, the game of football is characterized by various operations at different intervals, and thus the anaerobic energy system is in use more often. During interaction with differing combinations of low, medium, and high intensity football activities, the average oxygen consumption is $70 \%-80 \%$ of the maximum oxygen consumption rate (V02max), and the average heart rate is about $80 \%-90 \%$ of the maximum heart rate HRmax (Bangsbo, Mohr, 2006; Mohr, Krustrup, 2003).

Kraemer and Hakkinen (2002) explain that the ratio for high and low intensity work is $1: 7$. The average blood lactate level is from $2-10 \mathrm{mmol} / \mathrm{l}$, halfway through the final phase (normally, a match is split up into 15 minute intervals), the level increases (Gonçalves, Coutinho, 2017; Bloomfield, Polman, 2007; Bangsbo, Mohr, 2006; Mohr, Krustrup, 2003; Kraemer, Hakkinen, 2002). The data obtained is then used both to solve technical/tactical tasks and develop physical abilities. The used measuring devices (e.g. heart rate monitor, global positioning systems) enable workload dosage according to individual needs and the assessment of its compliance with pre-defined tasks.

The data gathered on a player's individual skills and abilities is crucial when assessing a football player's potential. There is a research (Höner, Leyhr, 2017; Gonaus, Müller, 2012; Unnithan, White, 2012; Gall, Carling, 2010; Williams, Reilly, 2010), for talent identification models, and the abilities and skills of young people are assessed to predict a football player's career opportunities and development directions. Over the course of this assessment process, football players' biomotor abilities, technical skills and other strengths are measured and analysed. The selection of football players, who play on a professional level (have participated in an official game) show better results. However, the assessment of results must also recognize young people whose biological age is behind their chronological age and therefore their development is delayed (Höner, Leyhr, 2017; Gonaus, Müller, 2012; Unnithan, White, 2012; Gall, Carling, 2010; Williams, Reilly, 2010; Reilly, Williams, 2010). Höner and Leyhr (2017) having surveyed 14178 young footballers (from the age of 12), their physical characteristics (speed and agility), as well as elementary footballing parameters, through a long term study concluded that the average effect size $(d=0.70)$ in speed parameters is between those who become professional footballers 
and those who do not reach the professional level. Gall and Carling (2010), working with speed parameters among youth players (U14), who reach a professional level (participating in an official match), as well as amateurs, found that the results were higher for the former, with a low effect size $(d=0.50)$ There is also a contrasting belief stating that it is not possible to use physical parameters to assess a football player's talent (Pankhurst, Collins, 2013; Buchheit, Simpson, 2012; Lidor, Côté, 2011; Franks, Williams, 1999). What is lacking in the testing of physical characteristics, according to Lidor and Côté (2011) is the failure to rate the match understanding components. Testing procedures do not include situational predictions of decision making. In addition, testing is done on an individual basis and does not include the demands of being part of a team game. However, it is possible to use the information acquired about an athlete's physical characteristics in the planning and execution of training. The information can also be adequately presented to the athlete, potentially serving as motivation for the player (Lidor, Côté, 2011).

The objective of the study: to develop the physical characteristic profile of FS "Metta" football players based on the data analysis of the applied study and to assess the practical application thereof to the improvement of the training process.

Study question: How to use physical characteristic testing parameters in order to evaluate the career development of a footballer and to improve training methods?

Within the research project, the authors will employ the biomotor ability test to define a footballer's maximum speed, agility and endurance. They also developed football players' profiles at FS "Metta" for the age group from U14 (people younger than 14) to U16. Furthermore, the obtained information will be used to improve the training process. In the long-term, this database will allow analysis of the gathered data in terms of the developmental direction of the football player's career. Therefore, this will allow the assessment and improvement the current training methods. In the view of Buchheit (2009), explaining a footballer's indicators in $5 \mathrm{~m}, 10 \mathrm{~m}$, and $20 \mathrm{~m}$ sprints, indicators about a players' acceleration are acquired, which gives no practical benefit the the improvement of the training process. However, in examining a footballer's maximum speed and $\mathrm{V}_{\text {YYIRT }}$, it is possible to use these values in the improvement of the training process. Therefore it is possible to adjust individual running speeds during interval training (Buchheit, Simpson, 2002, Buchheit, 2009). 


\section{Research methods}

The physical characteristic assessment protocol of football players includes the following tests: flying $20 \mathrm{~m}$ sprint, $\mathrm{T}$ agility test, Yo-Yo Intermittent Test (YYIRT) $1^{\text {st }}$ (up to U15 age group included) and $2^{\text {nd }}$ level. The physical characteristics are assessed three times per year:

1. On second week after resuming training in January.

2. In June or July, depending on the championship schedule and match dates.

3. After the end of the championship (November).

Test protocol: 20 min warmup, trial run, two attempts of flying $20 \mathrm{~m}$ sprint with at least three minutes of rest in-between the runs, trial run, and a $\mathrm{T}$ agility test with one attempt on the right side and one attempt on the left side. Both "Microgate Witty Wireless Training Timer" system to record time results. YYIR test is performed after the speed and agility tests. The testing results are registered with "Bitworks Team Beep Test" programme which also includes playing of an audio recording.

The average sprint/acceleration distance covered by players in team sports is $\sim 20 \mathrm{~m}$ and the start position takes place in movement (Brown, Vescovi 2012; Mohr, Krustrup, 2003). The maximum speed is reached in 20-30 m (Vescovi, Rupf, 2010). Based on the pre-defined information as to reaching the maximum speed, the authors used flying $20 \mathrm{~m}$ sprint with $25 \mathrm{~m}$ of run-up. The maximum speed is calculated.

The authors had previously learned from the football analysis sources that a player's manoeuvrability (agility) is an important aspect in football. The authors selected the $\mathrm{T}$ agility test as their core approach (Semenick, 1990), applying certain modifications (see Figure 1) so that the realization process would be as practical as possible (adopted from the Nike Football Academy, 2014). Unlike the initial test version, the type of movement is no longer regulated.

The game of football includes a certain regiment of intervals (e.g. slow or moderate intensity runs, sprints, jumps, stops) (Bloomfield, Polman, 2007; Bangsbo, Mohr, 2006; Mohr, Krustrup, 2003; Kraemer, Hakkinen, 2002). Therefore, to determine the football players' endurance (ability to recover in-between intensive outbursts, as well as the speed at which the participant comes to a stop $-\mathrm{V}_{\text {YYIRT }}$ ) the authors employed the YYIR test (Bangsbo, Iaia, 2008). The obtained $\mathrm{V}_{\text {YYIRT }}$ results can be used in the training process to develop interval exercises as close as possible to the maximum speed of oxygen uptake (vVO2max). When interpreting the obtained results, it must be remembered that $\mathrm{V}_{\text {YYIRT }}$ is lower than vVO2max and thus it must be considered when planning the training workloads (Buchheit, 2009). The $1^{\text {st }}$ level test which starts with $10 \mathrm{~km} / \mathrm{h}$ interval is performed by U14-U15 


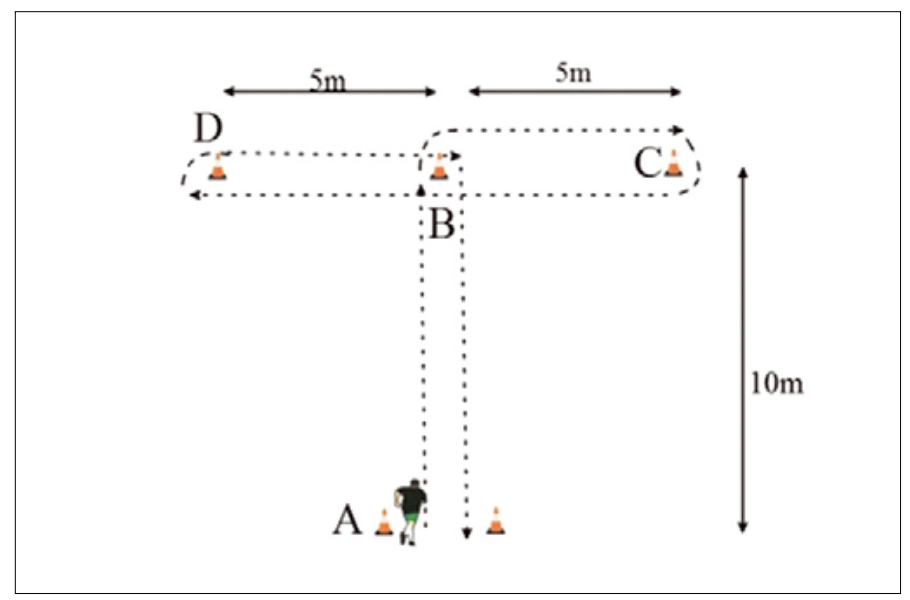

Figure 1. Nike Academy modification of the T agility test (adopted from the Nike Football Academy, 2014)

(included) age groups. The $2^{\text {nd }}$ level test which starts with $13 \mathrm{~km} / \mathrm{h}$ interval is performed by U16 and older athletes.

The Microsoft Excel program was used for statistical analysis. The obtained results were processed by the use of descriptive statistics. In order to develop the football players' profile in each age group, the authors used \pm standard deviation of average arithmetic values. When comparing the groups among themselves, the authors used student $t$ value for independent groups with the significance level $p<0.05$. Such methodology was employed because each age group had different methods as well as different composition of participants. Furthermore, each age group had its own coach. Therefore, age groups must be assessed as not connected. To determine the effect size of differences between the groups, we are to use the model developed by Hopkins W. G. (2010) according to which there is trivial $(d<0.2)$, low $(0.2<d<0.6)$, average $(0.6<d<1.2)$, high $(1.2<d<2.0)$ and very high $(2.0<d<4.0)$ level of significance.

\section{Results}

To develop FS “Metta" football players' profile, U14 group includes $n=61$ players. The total number of measurements in flying $20 \mathrm{~m}$ sprint and maximum speed -124 , YYIR test -120 and T agility test - 126. U15 group includes $n=55$ players. The total number of measurements in flying $20 \mathrm{~m}$ sprint and maximum speed - 116, YYIR test -106 and T agility test -111 . U16 group includes $n=52$ players. The total number of measurements in flying 20m sprint and maximum speed - 91, YYIR test - 79 and T agility test -87 . The results are not grouped according to player positions. 
Table 1. FS “Metta" football players' profile in respective age groups

\begin{tabular}{|c|c|c|c|c|c|}
\hline \multirow{2}{*}{$\begin{array}{c}\text { Age } \\
\text { group }\end{array}$} & $\begin{array}{c}\text { Plying 20 m } \\
\text { sprint, sec }\end{array}$ & $\begin{array}{c}\text { Max speed, } \\
\mathbf{k m} / \mathbf{h}\end{array}$ & $\begin{array}{c}\text { YYIRT, } \\
\mathbf{m}\end{array}$ & $\begin{array}{c}\text { T agility on } \\
\text { the right } \\
\text { side, } \\
\text { sec }\end{array}$ & $\begin{array}{c}\text { T agility on } \\
\text { the left side, } \\
\text { sec }\end{array}$ \\
\hline U14 & $2.65 \pm 0.16$ & $27.2 \pm 1.7$ & $\begin{array}{c}\text { YYIRT1 } \\
1170 \pm 516\end{array}$ & $9.85 \pm 0.40$ & $9.81 \pm 0.36$ \\
\hline & & & $\begin{array}{c}\text { YYIRT1 } \\
1460 \pm 652\end{array}$ & $9.69 \pm 0.38$ & $9.69 \pm 0.41$ \\
\hline U15 & $2.50 \pm 0.18$ & $28.97 \pm 2.05$ & YYIRT2 & & \\
U16 & $2.46 \pm 0.14$ & $29.4 \pm 1.7$ & $636 \pm 279$ & $9.48 \pm 0.34$ & $9.47 \pm 0.35$ \\
\hline
\end{tabular}

When comparing U14 and U15 age groups, the authors found out that the differences in flying $20 \mathrm{~m}$ sprint and subsequently the maximum speed were statistically reliable $(p<0.05)$ with average significance $(d=0.94)$. U15 football players are $0.15 \mathrm{sec}(1.7 \mathrm{~km} / \mathrm{h})$ faster than U14 football players (see Table 1). The differences between the age groups in the YYIR 1 test and the T agility test with turning to right are statistically reliable $(p<0.05)$ but with low level of significance: $290 \mathrm{~m}(d=0.51)$ and $0.16 \mathrm{sec}(d=0.41)$ in favour of U15. In terms of turning to left, the difference is statistically reliable. There is information suggesting that differences between the levels of different players cannot be observed in isolated agility actions. This can only be observed when the test also addresses the decision making-process in the context of football. The $\mathrm{T}$ agility test does not address this aspect (Trecroci, Milanović, 2018).

The comparison between U15 and U16 speed characteristics shows that the difference between both groups is neither significant nor statistically reliable. The endurance tests were not compared because execution was different. U16 football players were faster in the $\mathrm{T}$ agility tests in both right and left turns: 0.22 and $0.25 \mathrm{sec}$ respectively. These differences are statistically reliable $(p<0.05)$ with low level of significance $(d=0.59$, $d=0.58)$.

\section{Discussion}

When assessing the results from all of the work done in this study, it must be noted that measurements are taken without the context of football. As indicated by Trecroci and Milanovič (2018) having observed U15 footballers' agility, there is no difference between elites and average level footballers. Although the $\mathrm{T}$ agility test results characterize a football player's ability to accelerate speed and swiftly stop and change direction, it 
must be noted that the test is carried out without the context of a football game (decision-making) (Trecroci, Milanović, 2018).

Therefore, these results must be seen in conjunction with the performance in a football game in order to obtain even more accurate measurements for the football player's profile. In further studies, it is necessary to develop measurement/indicator methods with included assessment for understanding of football.

Physical characteristic differences can be seen in the transition from U14 to U15. It is possibly related to the rapid growth period (Fernāte, 2018). Furthermore, FS "Metta" training methodology employs specialized and football-related speed and endurance exercises starting from U15 age group. From U15 to U16, the physical characteristics differ in terms of agility. This could be explained by the fact that within a year after the rapid growth period (Fernāte, 2008) the body has adapted and thus the football player is more capable of controlling his own body in turns, accelerations and direction changes. The maximum speed once again improves from U16 to U17; however, to gain confirmation for the aforementioned statement, it is necessary to increase the data volume for the U17 age group.

The physical characteristics of FS "Metta" players (starting from U15 age group) who have played in an adult team are above the average profile of football players (maximum speed $=28.97 \pm 2.05 \mathrm{~km} / \mathrm{h}$, YYIR1 test $=1460 \pm 652 \mathrm{~m}, \mathrm{~T}$ agility test to right and left $=9.69 \pm 0.38$, $9.69 \pm 0.41 \mathrm{sec})$ and their speed results reach the elite level norms of adults ( $>30 \mathrm{~km} / \mathrm{h}$ ) (Andrzejewski, Chmura, 2015; Bangsbo, Mohr, 2006). Further studies are required to learn what level of athleticism is reached by football players with the respective results and whether these results are decisive to become a professional football player.

\section{Conclusions}

Based on the study's theoretical part, the authors conclude that the obtained information will improve the training process through forming groups with equal speed or durability characteristics, thus customizing a football player's training plan. The results obtained were used to develop football players' physical characteristic profiles (see Table 1), e.g.: U16 FS "Metta" football player can reach $29.4 \pm 1.7 \mathrm{~km} / \mathrm{h}$; in the same profile, the YYIR2 test results show $636 \pm 279 \mathrm{~m}$, where the $\mathrm{V}_{\text {YYIR2T }}=17.5 \pm$ $0.5 \mathrm{~km} / \mathrm{h}$, but the $\mathrm{T}$ agility test results show $9.48 \pm 0.34 \mathrm{sec}, 9.47 \pm$ $0.35 \mathrm{sec}$ in turns to right and left respectively. This gives a representation of FS "Metta" students (U14-U16) in the period from 2016 to 2018. The information acquired will allow the understanding of which parameters are necessary to reach the level of Latvian competition, foreign competition, 
or to remain at the amateur level. Upon gathering information about FS "Metta" students who have played professionally (played on the field in an adult game), it can be concluded that the adult level is reached by the players who exceed physical characteristics of U15 age group profile. However, it is still necessary to extend the data to clarify the desirable thresholds. Further studies on the same topic require introduction of results of understanding the game of football, as well as assessment of development of the football player's career after the age of 18, 21 and 25.

\section{References}

Andrzejewski, M., Chmura, J., Pluta, B., \& Konarski, J. (2015). Sprinting Activities and Distance Covered by Top Level Europa League Soccer Players. International Journal of Sports Science and Coaching, 10, 39-50. DOI: 10.1260/1747-9541.10.1.39.

Bangsbo, J., Iaia, F. M., \& Krustrup, P. (2008). The Yo-Yo intermittent recovery test: a useful tool for evaluation of physical performance in intermittent sports. Sports Med., 38(1), 37-51. Review. PubMed PMID: 18081366.

Bangsbo, J., Mohr, M., \& Krustrup, P. (2006). Physical and metabolic demands of training and match-play in the elite football player. Journal of Sports Sciences. Jul, 24(7), 665-74. Review. PubMed PMID: 16766496.

Bloomfield, J., Polman, R., \& O’Donoghue, P. (2007). Physical Demands of Different Positions in FA Premier League Soccer. Journal of Sports Sciences Med, 6(1), 63-70. eCollection. PubMed PMID: 24149226; PubMed Central PMCID: PMC3778701.

Brown, T. D. \& Vescovi, J. D. (2012) Maximum Speed: Misconceptions of Sprinting. Strength and Conditioning Journal, 34(2), 37-41. DOI: 10.1519/SSC.0b013e31824ea156.

Buchheit, M. (2009). The 30-15 Intermittent Fitness Test: 10 year review. Myorobie Journal, 1.

Buchheit, M., Simpson, B., Peltola, E., Mendez-Villanueva, A. (2012). Assessing Maximal Sprinting Speed in Highly Trained Young Soccer Players. International Journal of Sports Physiology and Performance, 7, 76-8. DOI: 10.1123/ijspp.7.1.76.

Drust, B., \& Green, M. (2013). Science and football: evaluating the influence of science on performance. Journal of Sports Sciences, 31(13), 1377-1382, DOI: $10.1080 / 02640414.2013 .828544$.

Fernāte, A. (2008) Vispusība - galvenais princips bērnu un jauniešu sportā. No: Bērnu un Pusaudžu Trenera Rokasgrāmata (Comprehensiveness - the main principles of youth and adolescent sports). Latvijas treneru tālākizglītības centrs. Rīga, p. 41.

Franks, A. M., Williams, A. M., Reilly, T., Nevill, A. (1999). Talent identification in elite youth soccer players: Physical and physiological characteristics. Communication to the $4^{\text {th }}$ World Congress on Science and Football, Sydney. Journal of Sports Sciences, 17, 812.

Gonaus, C., \& Müller, E. (2012). Using physiological data to predict future career progression in 14- to 17-year-old Austrian soccer academy players. Journal of Sports Sciences, 30(15). DOI: 10.1080/02640414.2012.713980.

Gonçalves, B., Coutinho, D., Santos, S., Lago-Penas, C., Jiménez, S., \& Sampaio, J. (2017). Exploring Team Passing Networks and Player Movement Dynamics in Youth Association Football. PLOS ONE, 12(1), e0171156. Retrieved from http://doi.org/10.1371/journal. pone.0171156. 
Höner, O., Leyhr, D., \& Kelava, A. (2017). The influence of speed abilities and technical skills in early adolescence on adult success in soccer: A long-term prospective analysis using ANOVA and SEM approaches. PLOS ONE, 12(8), e0182211. Retrieved from http:// doi.org/10.1371/journal.pone.0182211.

Hopkins W. G. (2010). Linear models and effect magnitudes for research, clinical and practical applications. Sportscience. 14. Retrieved from sportsci.org/2010/wghlinmod. htm; accessed on 10.02.2013.

Kraemer, J. W., \& Hakkinen, K. (2002). Strength Ttraining For Sport. Blackwel Science, pp. 75-91.

Le Gall, F., Carling, C., Williams, M., \& Reilly, T. (2010). Anthropometric and fitness characteristics of international, professional and amateur male graduate soccer players from an elite youth academy. $J$ Sci Med Sport, 13(1), 90-95. DOI: 10.1016/j. jsams.2008.07.004. Epub 2008 Oct 2. PubMed PMID: 18835220.

Lidor, R., Côté, J., \& Hackfort, D. (2011). ISSP position stand: To test or not to test? The use of physical skill tests in talent detection and in early phases of sport development. Int J Sport Exerc Psychol, 9. DOI: 10.1080/1612197X.2009.9671896.

Mohr, M., Krustrup, P., \& Bangsbo, J. (2003). Match performance of high-standard soccer players with special reference to development of fatigue. Journal of Sports Sciences, 21(7), 519-28. PubMed PMID: 12848386.

Mohr, M., Krustrup, P., \& Bangsbo, J. (2003). Match performance of high-standard soccer players with special reference to development of fatigue. Journal of Sports Sciences, 21, 519-528.

Nike Football Academy. (2014). Retrieved from https://www.nike.com/academy/ training/index.html.

Pankhurst, A., \& Collins, D. (2013). Talent identification and development: The need for coherence between research, system, and process. Quest, 65(1), 83-97. Retrieved from https://doi.org/10.1080/00336297.2012. 727374.

Reilly, T., \& Thomas, V. (1976). A motion analysis of work-rate in different positional roles in professional football match-play. Journal of Human Movement Studies, 2, 87-89.

Reilly, T., Williams, A. M., Nevill, A., \& Franks, A. (2010). A multidisciplinary approach to talent identification in soccer. Journal of Sports Sciences, 18(9), 695-702. DOI: 10.1080/02640410050120078.

Semenick, D. (1990) Tests and measurements: The T-test. NSCA J. 12(1), 36-37.

Trecroci, A., Milanović, Z., Frontini, M., Iaia, F. M., \& Alberti, G. (2018). Physical Performance Comparison between Under 15 Elite and Sub-Elite Soccer Players. Journal of Human Kinetics, 61, 209-216. Retrieved from http://doi.org/10.1515/hukin-2017-0126.

Unnithan, V., White, J., Georgiou, A., Iga, J., \& Drust, B. (2012). Talent identification in youth soccer. Journal of Sports Sciences, 30(15), 1719-26. DOI: $10.1080 / 02640414.2012 .731515$.

Vescovi, J. D., Rupf, R., Brown, T. D., \& Marques, M. C. (2010) Physical performance characteristics of high-level female soccerplayers 12-21 years of age. Scandinavian Journal of Medicine and Science in Sports, 11(11).

Williams, A. M., \& Reilly, T. (2010) Talent identification and development in soccer. Journal of Sports Sciences, 18(9), 657-667. DOI: 10.1080/02640410050120041. 